\title{
Analysis and Computational Study of a High Chimney Tower for Solar Energy
}

\author{
Rahui Sahar ${ }^{1}$, Pr. Bousshine Lahbib ${ }^{2}$ \\ ${ }^{1}$ Laboratory of construction technology and industrial systems, High National School of Electricity and \\ Mechanic / Hassan II University-Casablanca, MOROCCO \\ ${ }^{2}$ Laboratory of construction technology and industrial systems, High National School of Electricity and \\ Mechanic / Hassan II University -Casablanca, MOROCCO
}

\begin{abstract}
A Solar Chimney Power Plant consists of central chimney that is surrounded by a transparent canopy locateda few meters above ground level. An analysis of solar chimneys has been developed, aimed particularly to study stability and structural strength of a model of cylindrical reinforced concrete tower with $500 \mathrm{~m}$ in tall and 50m in diameter. The design of this tower has several technical challenges. This model is subjected to his own weight, the effects of wind and the pressure due to the flow of air inside the chimney. In this study, the effect of these loads on the stability and strength of the chimney has been examined. The ringsstiffened are necessary to prevent ovalisation of the structure. In addition, the influence of various designs of rings-stiffened is taken into consideration in the mechanical behaviour of this tower. Numerical simulation modeling method based on finite element method is adopted using the "Autodesk Robot structural analysis professional" software.
\end{abstract}

Keywords: Solar Chimney Power Plant, Cylindrical Tower, Reinforced Concrete, Dimensioning, Ringstiffeners, Pressure, Wind Loads, Numerical Simulation.

\section{Introduction}

A Solar Chimney Power Plant is a solar power generating facility, which uses solar radiation to increase the internal energy of air flowing through the system, thereby converting solar energy into kinetic energy. The kinetic energy from the air is then transformed in electricity by use of a suitable turbine. A Solar Chimney Power Plant consists of three main components: the solar collector (1), the chimney (2), and one or more turbo generators (3) (Fig. 1). Through the coinciding change in air pressure, the air moves radially towards the center, where it enters the tower, which creates an up-draught. By this suction effect, hot air is drawn in from the collector and as it rises up the chimney, it flows through either one large turbine, or numerous smaller turbines, the preferred option yet to be determined. These turbines are linked to conventional generators, whereby electricity is generated. The collector can be equipped with a water-storage system (4) to increase the power production during the night.

A $50 \mathrm{~kW}$ prototype solar chimney plant, with tower height $200 \mathrm{~m}$ and collector diameter $10 \mathrm{~m}$, was built in Manzanares, Spain in 1982. Performance measurements on thisexperimental plant proved the solar tower concept to be technically reliable [1,2]and potentially economically viable [3]. Since then, detailed studies of the performance of a solar chimney were performed and reported by Gannon and von Backström [4], Kröger\& Buys [5]and Pretorius \&Kröger [6]. Padki and Sherif [7] discussed in brief the effects of the geometrical and operating parameters on the chimney performance. Pasumarthi and Sherif [8] conducted a study to demonstrate that solar chimney technology is a viable alternative energy technology suitable and adaptable to hot climate areas such as those of Morocco.

\section{Problem Statement}

\section{A. characteristics of the chimney:}

The power output of Solar Chimney Power Plant depends on parameters such as the ambient conditions (insolation, ambient temperature, and wind velocity) and dimensions of chimney and collector. Therefore, any economic solution must have a tower of a significant height[9]. The characteristics of the chimney are:

- It is a thermal machine: a mechanism for performing a job using heat sources of various temperatures;

- The friction losses are minimal;

- The effectiveness of the Solar Chimney does not depend on the temperature of the incoming air, but to the temperature difference with the outside air above the chimney.

\section{B. Conceptual design and Geometry of the tower structure:}

In the present study, an analysis of the model of towerused in solar chimney power plant has been developed. The total height of the tower is $500 \mathrm{~m}$. A tower has a constant diametermeasuring $50 \mathrm{~m}$. their 
thicknesses ranges from $0.2 \mathrm{~m}$ on the top to $0.4 \mathrm{~m}$ above foundation, this thickness may be necessary to enable the walls bear the weight of the concrete located above them [10]. A tower can be considered as

\begin{tabular}{|c|c|c|c|}
\hline \multicolumn{4}{|c|}{ Nomenclature: } \\
\hline$E_{C}$ & Young's modulus of concrete [MPa] & $\mathrm{t}$ & thickness of the shell [m] \\
\hline$f_{c m}$ & compression strength of concrete [MPa] & $L_{e}$ & effective shell length [m] \\
\hline$f_{c t m}$ & tension strength of concrete [MPa] & $h_{w}$ & web height $[\mathrm{m}]$ \\
\hline$E_{S}$ & Young's modulus of steel [MPa] & $t_{w}$ & web thickness [m] \\
\hline$f_{y m}$ & yield strength of steel [MPa] & $t_{f}$ & flange thickness [m] \\
\hline$f_{t m}$ & tension strength of steel [MPa] & $b_{f}$ & flange breadth [m] \\
\hline $\mathrm{q}$ & dynamic pressure of the wind $\left[\mathrm{daN} / \mathrm{m}^{2}\right]$ & $L_{r}$ & ring spacing $[\mathrm{m}]$ \\
\hline $\mathrm{q}_{10}$ & dynamic pressure of the wind at the height $\mathrm{H}=10 \mathrm{~m}\left[\mathrm{daN} / \mathrm{m}^{2}\right]$ & $\mathrm{n}$ & number of rings stiffened [-] \\
\hline $\mathrm{k}_{\mathrm{H}}$ & height effect [-] & $G_{W}$ & axial load [N] \\
\hline$k_{S}$ & site effect [-] & $M_{W}$ & bending moment [N.m] \\
\hline$k_{m}$ & mask effect [-] & $\mathrm{G}$ & dead load \\
\hline $\mathrm{T}$ & resultant of the normal forces of the wind [daN/m] & $\mathrm{P}$ & live load \\
\hline$T_{t}$ & air temperature inside the chimney [K] & $\mathrm{W}$ & wind load \\
\hline$T_{t, i n}$ & air temperature inside the chimney at $\mathrm{z}=0[\mathrm{~K}]$ & \multirow{2}{*}{\multicolumn{2}{|c|}{ Greek symbols: }} \\
\hline $\mathrm{k}$ & specific heat ratio [-] & & \\
\hline$p_{t}$ & air pressure inside the chimney $[\mathrm{Pa}]$ & $v_{c}$ & Poisson's ratio of concrete[-] \\
\hline$p_{t}(0)$ & air pressure inside the chimney at $\mathrm{z}=0[\mathrm{~Pa}]$ & $v_{S}$ & Poisson's ratio of steel[-] \\
\hline$\rho_{t}$ & air density inside the chimney $\left[\mathrm{kg} \cdot \mathrm{m}^{3}\right]$ & $\delta$ & dimension effect $[-]$ \\
\hline$\rho_{t}(0)$ & Air density inside the chimney at $\mathrm{z}=0\left[\mathrm{~kg} \cdot \mathrm{m}^{3}\right]$ & $\beta$ & dynamic amplification [-] \\
\hline$R_{l}$ & ideal gas constant, $287.05\left[\mathrm{~J} . \mathrm{kg}^{-1} \cdot \mathrm{K}^{-1}\right]$ & $\sigma_{a}$ & axial stress [MPa] \\
\hline $\mathrm{g}$ & acceleration of gravity $\left[\mathrm{m} / \mathrm{s}^{2}\right]$ & $\sigma_{b}$ & bending stress $[\mathrm{MPa}]$ \\
\hline $\mathrm{R}$ & radius of the tower $[\mathrm{m}]$ & $\sigma_{c r}$ & critical stress buckling [MPa] \\
\hline $\mathrm{H}$ & height of the tower [m] & & \\
\hline
\end{tabular}

Circular cylindrical shell, because, the ratio of the radius $50 \mathrm{~m}$ to shell thickness isgreater than ten. (Fig. 2) For the construction of the tower, an advanced high performance concrete is used for building the wall [11].Basic properties of this reinforced concrete are given in Table 1.

\begin{tabular}{|l|l|}
\hline Concrete & Reinforcement steel \\
\hline $\boldsymbol{E}_{\boldsymbol{c}}=\mathbf{3 2 0 0 0} \mathbf{M P a}$ & $\boldsymbol{E}_{\boldsymbol{s}}=2,1.10^{5} \mathrm{MPa}$ \\
\hline $\mathbf{v}_{\boldsymbol{c}}=\mathbf{0 . 2}$ & $\mathbf{v}_{\boldsymbol{s}}=0.3$ \\
\hline $\boldsymbol{f}_{\boldsymbol{c m}}=\mathbf{3 5 0 0} \mathbf{M P a}$ & $\boldsymbol{f}_{\boldsymbol{y m}}=5.10^{2} \mathrm{MPa}$ \\
\hline $\boldsymbol{f}_{\boldsymbol{c t m}}=\mathbf{2 . 6 7} \mathbf{M P a}$ & $\boldsymbol{f}_{\boldsymbol{t m}}=5,5.10^{2} \mathrm{MPa}$ \\
\hline
\end{tabular}

Table 1: Properties of the reinforced concrete

To strengthen reinforced concrete towers, JorchSchlaich, German architect and project manager of the Manzanares solar chimney prototype in Spain [12], developed in his book "The Solar Chimney" [13], a principle called "principle of the egg and the bicycle wheel". This concept allows to place throughout the height of the tower rings stiffened as bicycle wheels to provide additional strength to the shell that would collapse very easily if not reinforced.Radial cables pulling directly on the concrete could undermine it, JorchSchlaich proposes to insert a ring stiffened by these rays will oppose any roundness of the vertical cylinder under the effect of the wind [14]. In the present study, we consider a number of rings stiffened $n=10$. (Fig. 2)

\section{Assessment Of Forces Acting On The Structure:}

The structure is subjected to combined loading. In general, the loads that act on the solar chimney are:

- Own weight of the structure

- Wind loads

- Pressure inside the chimney

- Earthquake loads

- Installation loads.

In this study, the emphasis is placed on the evaluation of the first three load cases: own weight of the structure, wind loads and pressure inside the tower. 


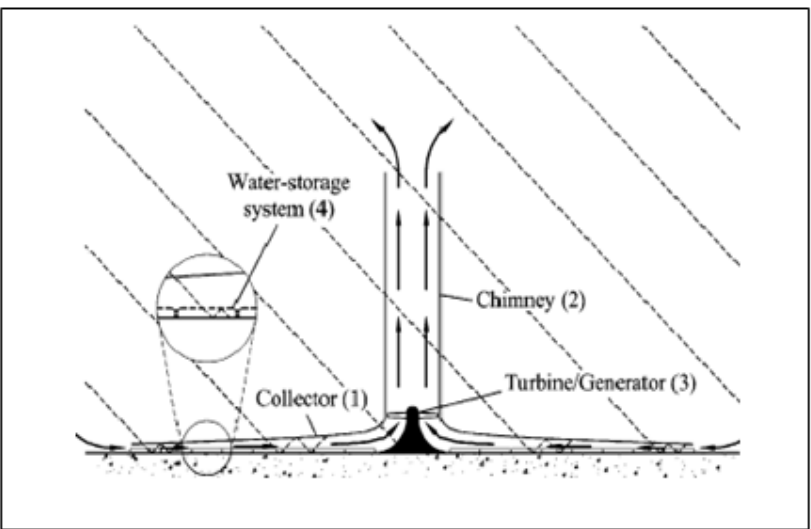

Fig. 1: Schematic drawing of a solar chimeny power plant

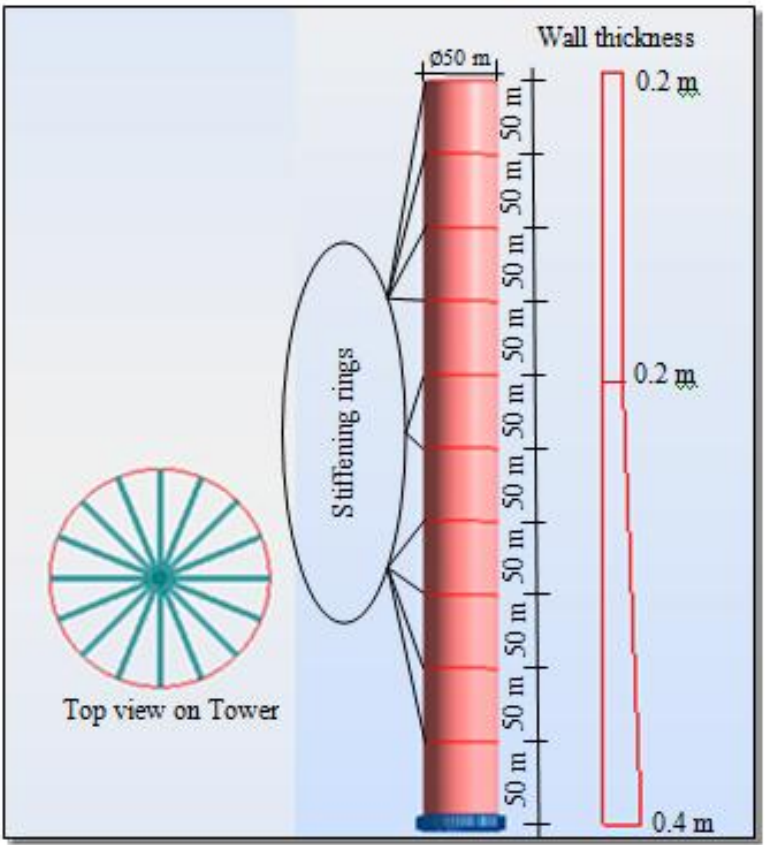

Fig. 2: Conceptual design and Geometry of the tower structure

\section{AWind loads:}

The height of the tower ranks among the sensitive structures to wind. For this reason, it makes use of construction standards (NV65) to accurately quantify the wind loads that the tower will have to endure. According to the NV65 [15], the wind pressure is calculated by the following formula:

$$
q=q_{10} K_{H} K_{s} K_{m} \delta \beta
$$

(1)

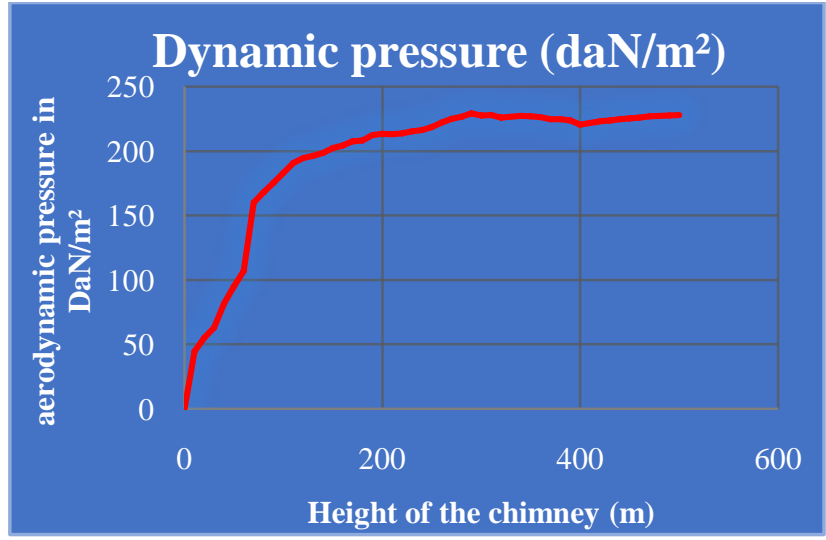

Fig. 3: Variation of the dynamic pressure in function of the height of the chimney 
The total resultant of the forces in the direction of the wind, on the body construction (called drag) is calculated by:

$\mathrm{T}=c_{t} q_{H n}$

(2)

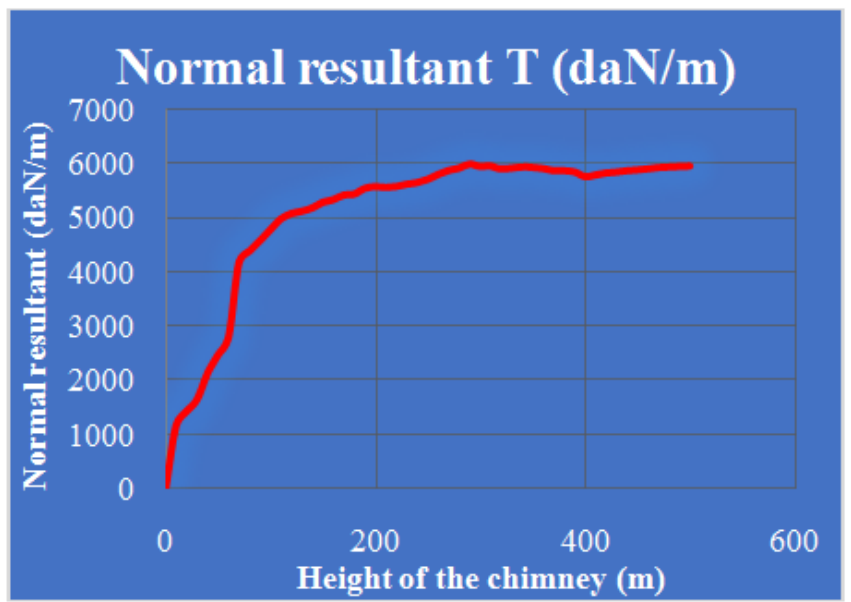

Fig. 4: Variation of the resultant of the normal forces (drag) in function of the height

\section{Pressure inside the chimney:}

The chimney converts the thermal energy produced by the collector into kinetic energy. Pressure, temperature and density variation of air inside the chimney is calculated considering an adiabatic expansion process [16]. Thus:

$T_{t}(z)=T_{t, i n}(0)\left(1-\frac{k-1}{k} \frac{z}{H_{0}}\right)$
$p_{t}(z)=p_{t}(0)\left(1+\frac{k-1}{k} \frac{z}{H_{0}}\right)^{k /(k-1)}(4)$
$\rho_{t}(z)=\rho_{t}(0)\left(1+\frac{k-1}{k} \frac{z}{H_{0}}\right)^{1 /(k-1)}(5)$

With:

$H_{0}=\frac{R_{l} T_{t, i n}}{g}$

And $\mathrm{k}=1.4005$

The pressure inside the chimney varies linearly with the height as shown in the figure 5:

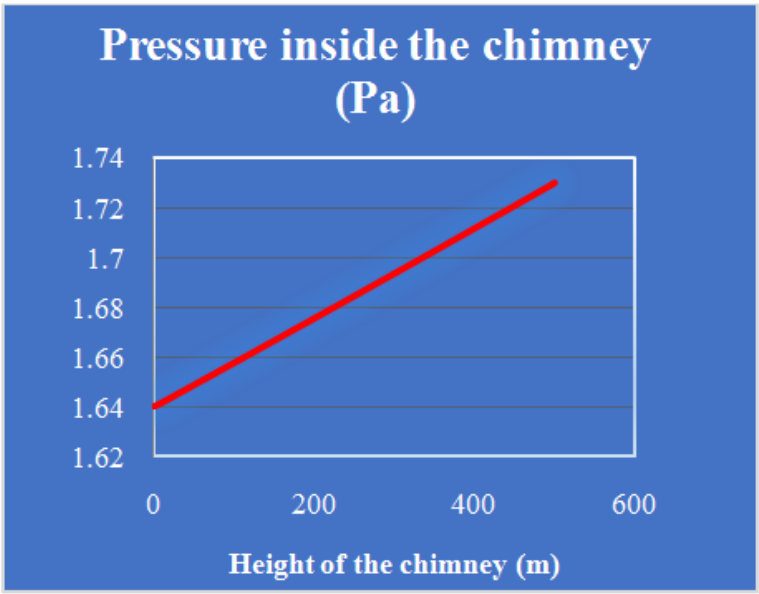

Fig. 5: Variation of the pressure inside the chimneyin function of the height of the chimney

\section{Basics of Ring-Stiffened Cylindrical Shell:}

To predict the failure modes (general instability, axisymmetric yielding and asymmetric buckling of the shell), failure pressures and characteristicsof ring stiffened cylindrical shells, a various methods (analytical solutions, classification society design rules, numerical analysis tools) have been used. 
Design rules for the shell buckling strength have been worked by ECCS [17], API [18] and DNV [19].

The dimensions of interest for analyzing ring-stiffened cylinders are related to the cylinder (shell) itself and the ring-stiffeners (frames). General Stiffener Dimensions are represented belowin Figure 6.

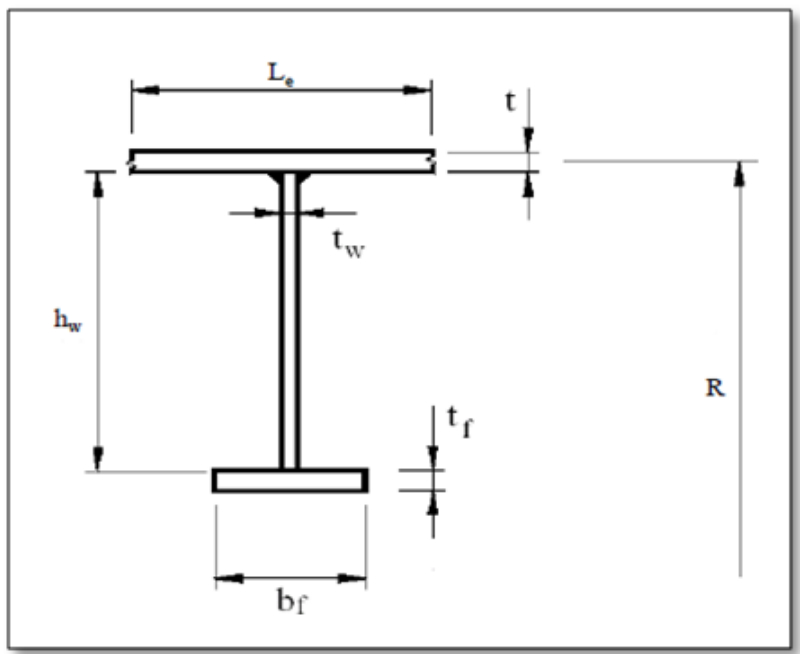

Fig. 6: General ring stiffened dimensions

$L_{e}$ is the effective length, it was calculated using the equation from Pulos and Salerno showen [20] below:

$L_{e}=1.56 \sqrt{R t}\left[\frac{\cosh (\theta)-\cos (\theta)}{\sinh (\theta)+\sin (\theta)}\right]$

Where:

$\theta=\sqrt[4]{3\left(1-v^{2}\right)} \frac{H}{\sqrt{R t}}$

$\theta=234.68$ and $L_{e}=3.488 \mathrm{~m}$

In the present study,the design rules of Det Norske Veritas (DNV) [21] are used for ring-stiffened cylindrical shell. The DNV design rules treats the buckling stability of shell structures based on the load and resistance factor design format (LRFD). They contains semi-empirical formulations forevaluating the buckling strength of stiffened cylindrical shells.

According to Det Norske Veritas [19], the sum of the axial $\sigma_{a}$ and bending $\sigma_{b}$ stresses should be less than the critical buckling stress, i.e.:

$\sigma_{a}+\sigma_{b}=\frac{G_{w}}{2 R \pi t}+\frac{\gamma M_{w}}{\pi R^{2} t} \leq \sigma_{c r}=\frac{f_{y}}{\sqrt{1+\lambda^{4}}}(9)$

Where:

$\lambda^{2}=\frac{f_{y}}{\sigma_{a}+\sigma_{b}}\left(\frac{\sigma_{a}}{\sigma_{E a}}+\frac{\sigma_{b}}{\sigma_{E b}}\right)(10)$

$\sigma_{E a}=(1.5-50 \beta) C_{a} \frac{\pi^{2} E}{12\left(1-v^{2}\right)}\left(\frac{t}{L_{r}}\right)^{2}(11)$

$\sigma_{E b}=(1.5-50 \beta) C_{b} \frac{\pi^{2} E}{12\left(1-v^{2}\right)}\left(\frac{t}{L_{r}}\right)^{2}(12)$

$C_{a}=\sqrt{1+\left(\rho_{a} \xi\right)^{2}}(13)$

$C_{b}=\sqrt{1+\left(\rho_{b} \xi\right)^{2}}$

$\rho_{a}=0.5\left(1+\frac{R}{150 t}\right)^{-0.5}$

$\rho_{b}=0.5\left(1+\frac{R}{300 t}\right)^{-0.5}$

$\xi=0.702 Z$;

$Z=\frac{L_{r}{ }^{2}}{R t} \sqrt{1-v^{2}}$

And $L_{r}=\frac{H}{n+1}$

According to the API design rules [18], the dependence of $\sigma_{E a}$ and $\sigma_{E b}$ on $L_{r}$ is very small. From equations (9) and (10), it can be deduced that $\sigma_{E a}$ and $\sigma_{E b}$ do not depend on $L_{r}$, since $L_{r}$ is in the denominator.

The factor of $(1.5-50 \beta)$ can be calculated as follows [22]. The maximum radial deformation of the shell caused by the shrinkage of a circumferential weld is:

$u_{\max }=0.64 A_{t} t \sqrt{R / t}(19)$ 
$A_{t} t$ is the area of specific strains near the weld. According to results of Farkas and Jarmai [23]:

$A_{t} t=0.844 .10^{-3} Q_{t}(20)$

Where:

$Q_{t}=60.7 A_{w} \quad(21)$

When: $t \leq 10 \mathrm{~mm}, A_{w}=10 t$

When: $t>10 \mathrm{~mm}, A_{w}=3.05 t^{1.45}$

The shell buckling strength should be multiplied by theimperfection factor $(1.5-50 \beta)$ where a reduction factor is introduced for which:

$0.01 \leq \beta=\frac{u_{\max }}{4 \sqrt{R t}}<0.02$

$\beta=0.01$ for $\frac{u_{\max }}{4 \sqrt{R t}}<0.01 \quad$ and

$\beta=0.02$ for $\frac{u_{\max }}{4 \sqrt{R t}} \geq 0.02$

Summary:

- $\mathrm{n}=10$ so $L_{r}=45.45 \mathrm{~m}$

- $\beta=0.01$ so $(1.5-50 \beta)=1$

- $\rho_{a}=0.37$ and $\rho_{b}=0.42$

- $\quad Z=394.11$ and $\xi=276.66$

- $C_{a}=102.1$ and $C_{b}=116.2$

- $\sigma_{E a}=210 \mathrm{Mpaand} \sigma_{E b}=420 \mathrm{MPa}$

- $\sigma_{a}=11 \mathrm{Mpa}$ and $\sigma_{b}=37.76 \mathrm{MPa}$

- $\lambda^{2}=1.45$ so $\sigma_{c r}=282.75 \mathrm{MPa}$

$\Rightarrow \quad \sigma_{a}+\sigma_{b} \leq \sigma_{c r}$

\section{Modelisation and mesh:}

\section{Numerical simulation}

Stiffened shells are widely used in offshore structures, bridges, towers, etc. stiffing rings can used to strengthen the shape of cylindrical shells. In our case, the shell is loaded by a combined load. The first step is to get the correct building codes (specification), structural analysis and design loads of cylindrical tower is based on NV65 rules [15]. Then, we need to calculate the forces, strains, deflections and deformations, caused by the combination of loads that will assault the structure. Main loading conditions for this structure are dead weight G, wind load $\mathrm{W}$ and pressure inside the chimney due to the air flow $\mathrm{P}$.

The final design analysis of stresses and deformations for all single load cases has been computed within standard linear finite element techniques, using the software system Autodesk Robot structural analysis professional which provides a comprehensive set of tools to model and analyze building as well as other large and complex structures.

In this study, various mechanical designs have been realized in order to choose the one which satisfy the conditions of stability and strength.

Figure 7 gives general impression of the applied discretization and boundary conditions.

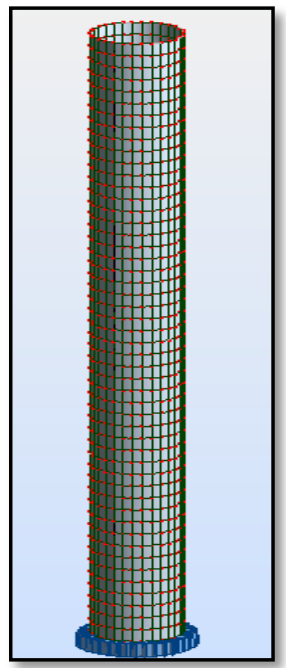

Fig. 7: FE for final tower design 
According to the BAEL 91, the tower has been analyzed for the following limit states:

- $\quad$ Serviceability limit state (SLS):

$G+P+W$

- Ultimate limit state (ULS):

$1.35 G+1.5 P+1.8 W$

E. Results and analysis:

i. Structure without ring stiffeners: A study of the tower without ring stiffeners has been realized toevince the importance of those elements.

- Technical description: the structure is composed of panels. Their thicknesses range from $0.2 \mathrm{~m}$ on the top to $0.4 \mathrm{~m}$ above the ground. The calculation model east of shell type. The type of reinforcement is reinforced concrete shell. The list of loads acting on the structure and the combinations of loads is shown in the following table:

\begin{tabular}{|l|l|l|l|}
\hline Case & Name of case & Nature & Type of analysis \\
\hline 1 & Own weight & Dead load & Linear static \\
\hline 2 & Internal pressure & Live load & Linear static \\
\hline 3 & Wind w+ & Wind load & Linear static \\
\hline 4 & Wind w- & Wind load & Linear static \\
\hline 5 & Comb1 & ULS & Linear combination \\
\hline 6 & Comb2 & SLS & Linear combination \\
\hline
\end{tabular}

Table 2: loads actingon the structure and the combinations of loads

- The results of the static analysis of the structure show that the total displacements of the tower reaches 2.63 $\mathrm{m}$ for the ultimate limit state and $1.46 \mathrm{~m}$ for the serviceability limit state. The maximum Von Mises equivalent stress is worth 37.01 MPa for ULS and 23.27 MPa for the SLS. It is located at the base of the structure. So here we have a large deformation of the tower, whence the need for additional rigid elements. (Fig. 8)

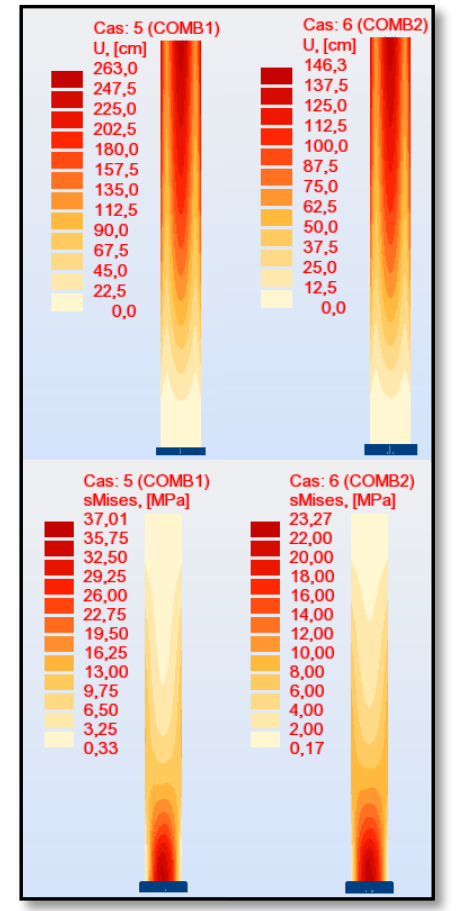

Fig. 8: Total displacements and Von Mises stresses of the Structure without ring stiffeners

\section{ii. Reinforced structure with two beams:}

Description of the design: we keep the same geometry, the same boundary conditions, and the same loads acting on the structure thus the same building material.Ten ring stiffeners have been placed to reinforce the structure. Every ring stiffener is composed by two beams. Thelatterelements are reinforced concrete beams. Results indicate that the both total displacements and Von Mises equivalent stresses are widely decrease. (Fig. 9) 


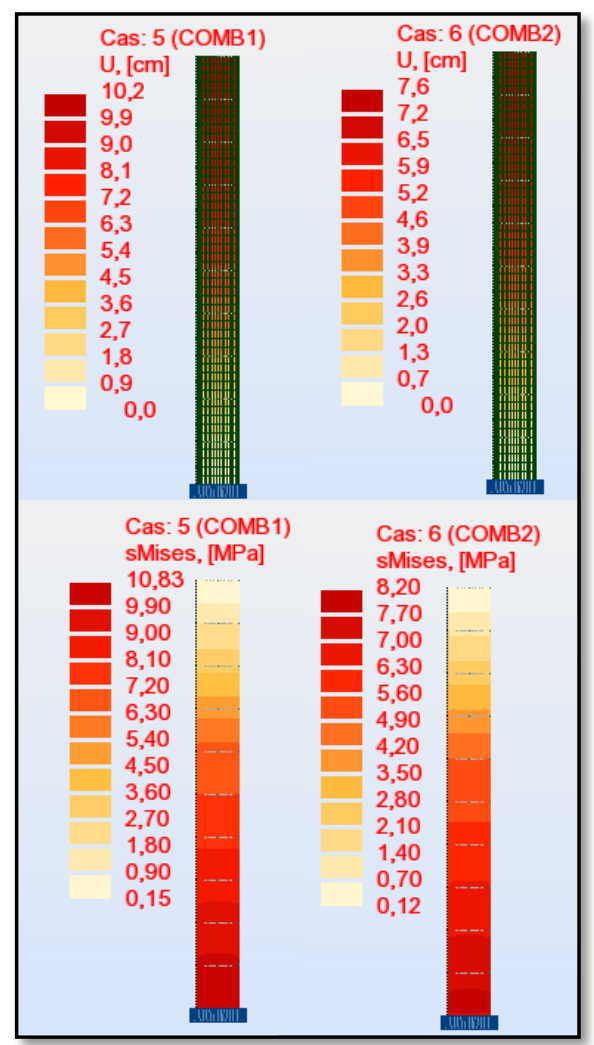

Fig. 9: Total displacements and Von Mises stresses of the reinforced structure with two beams

\section{iii. Reinforced structure with four beams:}

In this case, the lightest a drop at the total displacements and Von Mises equivalent stress is observed. We can say that there is an influence of the addition of the beams on the reinforcement of the tower. But, it must not put an excessive number of rays of the ring-stiffeners for wind turbine generators and other accessories be able to place inside the chimney. It should place an optimum number of those elements to reinforce the structure.

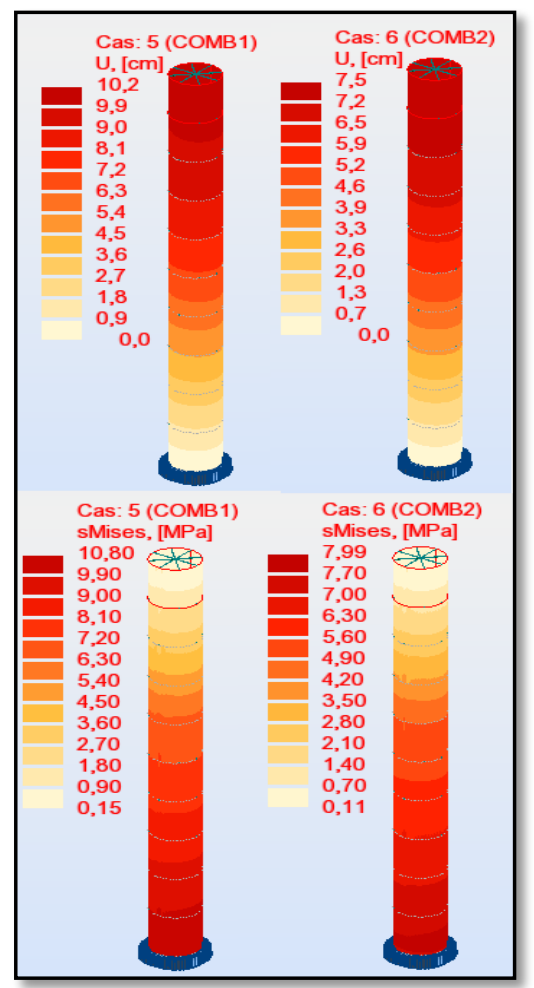

Fig. 10: Total displacements and Von Mises stresses of the reinforced structure with four beams 


\section{Conclusion\& Synthesis:}

Themain aimof this paper is to study and to determine the various parameters influencing the design of high chimney towers via an example of a model of a cylindrical tube with a height of $500 \mathrm{~m}$ and a diameter of $50 \mathrm{~m}$ constructed of reinforced concrete. Firstly, a brief introduction of the solar chimney power plant concept is given and the fields of research associated with the concept are presented. A description of the characteristics of the chimney and also an illustration of the conceptual design and geometry of the tower structure are provided. Afterwards, an analysis of the forces acting on the structure is identified. Then, the basics of ring-stiffened cylindrical shell are given to determine their characteristics. In the end, Numerical simulations based on finite element method are executed using the "Autodesk Robot structural analysis professional" software.The essentialsynthesis to be derived from this study are:

- The pressure inside the chimney due to the flow of air is negligiblecompared with the effectsof the wind and the weight of the structure.

- An important component in the structural design is the wind loading: the structural behaviour is that of a shell exposed to inhomogeneous fluctuating pressure distributions.

- The number of ring-stiffeners $n=10$ is sufficient to verify the condition of resistance of the chimney of height $\mathrm{H}=500 \mathrm{~m}$.

- The addition of the rigid elements is essential to increase the rigidity and the stability of the tower.

\section{References}

[1] Schlaich, J., 1994. The Solar Chimney: Electricity from the Sun. Deutsche Verlags-Anstalt, Stuttgart.

[2] Haaf, W., 1984. Solar chimneys, part II: Preliminary test results from the Manzanares pilot plant. Int. J. SolarEnergy 2, 141-161.

[3] Haaf, W., Friedrich, K., Mayr, G., Schlaich, J., 1983. Solar chimneys, part I: Principle and construction of thepilot plant in Manzanares. Int. J. Solar Energy 2, 3-20.

[4] Gannon, A.J., von Backstro“ m, T.W., 2000. Solar chimney cycle analysis with system loss and solar collectorperformance. J. Solar Energy Eng. 122, 133-137.

[5] Kröger, D.G. \& Buys, J.D., 2001. Performance evaluation of a solar chimney power plant. ISES 2001 Solar World Congress, Adelaide, South Australia.

[6] Pretorius, J.P., Kro“ ger, D.G., 2006. Critical evaluation of solar chimney power plant performance. Solar Energy 80 (5), 535-544.

[7] Padki, M.M., Sherif, S.A., 1992.A mathematical model for solarchimneys. In: Proceedings of 1992 International RenewableEnergy Conference, Amman, Jordan, Vol. 1, pp. 289-294.

[8] Pasumarthi, N., Sherif, S.A., 1997. Performance of a demonstrationsolar chimney model for power generation. In: Proceedings of the 35th Heat Transfer and Fluid Mechanics.

[9] Pablo González, Gascón y Marín, Guillermo Gómez Fontecha, Ole Geisen, « Les tours solaires: Deux approches pour utiliser l'énergie du soleil », 2011, PP 6

[10] Rahui S., Lahbib B., Jalal S.,Etude de la déformabilité d'une tour cylindrique en béton armé de hauteurH = 500m,1ère Conférence Internationale sur la Mécanique des matériaux et des structures MSM2014, Marrakech, Morocco, pp 491-499.

[11] Dieter Busch, Reinhard Harte, Wilfried B. Kratzig, Ulrich Montag, New natural draft cooling tower of $200 \mathrm{~m}$ of height, Engineering Structures 24 (2002) 1509-1521.

[12] Article en deux parties publiées dans International Journal of Solar Energy ; "Part 1 : Principle and Construction of the Pilot Plant in Manzanares", de W. Haaf, K. Friedrich, G. Mayr et J. Schlaich, 1983, Vol. 2, pp. 3-20 ; et "Part 2 : Preliminary Test Results from the Manzanares Pilot Plant", W. Haaf, 1984, vol. 2, 141-161.

[13] The Solar Chimney: Electricity from the sun, Jörg Schlaich, Éditions Axel Menges, 1995 pour l'édition anglaise.

[14] Tension structures for solar electricity generation, J. Schlaich, 1999, Engineering Structures 21, 658-668.

[15] NV 65 rules (DTU P06-002) (April 2000): "Rules defining the effects of snow and wind on buildings and annexes", Chapter III wind effects: $2-4-7$ part.

[16] M. A. dos S. Bernards, A. Vob, G. Weinrebe, Thermal and thechnical analyses of solar chimneys, Solar Energy 75 (2003) $511-524$.

[17] European Convention of Constructional Steelwork(ECCS) Recommendations for Steel Construction. Bucklingof steel shells. No. 56, Brussels, 1988.

[18] American Petroleum Institute (API) Bulletin 2U. Bulletinon stability design of cylindrical shells. 2nd ed. Washington,2000

[19] Det Norske Veritas (DNV): Buckling strength analysis.Classification Notes. No. 30.1, Hovik, Norway, 1995.

[20] J. G. Pulos and V. L. Salerno, "Axisymmetric Elastic Deformations and Stresses in aRing-Stiffened, Perfectly Circular Cylindrical Shell Under External Hydrostatic Pressure,” West Bethesda, MD. David Taylor Model Basin Report 1497, 1961.

[21] Det Norske Veritas, Recommended Practice on Buckling Strength of Shells. DNV-RPC202,Norway: Det Norske Veritas, 2002

[22] Farkas J. Thickness design of axially compressed unstiffened cylindricalshells with circumferential welds. Weld World 2002;46(11-12):26-9.

[23] Farkas J, J'armai K. Analysis of some methods for reducing residual beam curvatures due to weld shrinkage. Weld World 1998;41(4):385-98. 